\title{
EDITORIAL
}

\section{Intravenous iloprost for pulmonary arterial hypertension: still waiting for evidence}

\author{
S. Provencher* and O. Sitbon ${ }^{\#}$
}

I rrespective of its aetiology, pulmonary arterial hypertension $(\mathrm{PAH})$ is a serious disorder that results in right ventricular dysfunction, functional impairment and, ultimately, right heart failure and death. Over the last 20 yrs, significant advances in our understanding of the disease have led to the development of new, specific treatments. In 1996, a placebo-controlled trial demonstrated significant survival benefit with intravenous epoprostenol in severe idiopathic $\mathrm{PAH}$ [1]. Observational studies also suggested epoprostenol was associated with improved long-term outcomes [2, 3]. Subcutaneous treprostinil was subsequently shown to improve exercise capacity in PAH [4]. More recently, i.v. treprostinil was approved for use by the US Food and Drug Administration in cases of intolerable subcutaneous infusion site pain based on a bioequivalence study [5] and prospective open-label trials [6, 7]. Finally, randomised placebo-controlled trials documented the efficacy of inhaled iloprost either as monotherapy [8], or in addition to bosentan [9]. These drugs are now part of the recommended treatment algorithm for $\mathrm{PAH}$ [10], together with endothelin receptor antagonists and phosphodiesterase type- 5 inhibitors.

Conversely, data on clinical efficacy of i.v. iloprost in PAH have been scarce. Iloprost is a stable synthetic analogue of prostacyclin [11]. It possesses several pharmacological advantages over epoprostenol including enhanced chemical stability at room temperature and increased half-life, resulting in less frequent reservoir changes and the potential to avoid lifethreatening events in case of sudden infusion interruption. Short-term open-label [12] and observational [13] studies suggested i.v. iloprost was effective in improving exercise capacity and pulmonary haemodynamics in PAH. However, these studies were limited in size (eight and 13 patients treated with iloprost [12, 13], respectively) and included heterogeneous forms of pulmonary hypertension. Intravenous iloprost was never evaluated in a formal randomised placebocontrolled trial. It is noteworthy that despite a similar mode of action, the demonstration that inhaled iloprost and other parenteral prostacyclins are effective in treating $\mathrm{PAH}$ does not mean i.v. iloprost is equally effective. Indeed, apart from

*Centre de recherche de I'Institut Universitaire de Cardiologie et de Pneumologie de Québec Québec, Canada. ${ }^{\#}$ Centre de Référence National de I'HTAP, Service de pneumologie, UPRES EA2705, Hôpital Antoine-Béclère, AP-HP, Université Paris, Clamart, France.

CORRESPONDENCE: S. Provencher, Centre de recherche de I'Institut Universitaire Cardiologie et de Pneumologie de Québec, 2725 Chemin Ste-Foy, Québec, G1V 4G5 Canada. E-mail: Steve.Provencher@crhl.ulaval.ca differences in pharmacokinetics and pharmacodynamics, the potency and additional effects of prostacyclins appear to be specific to each compound [11]. Consequently, the efficacy of parenteral iloprost for PAH remains largely unknown, and i.v. iloprost is not currently recommended for the treatment of PAH [10]. Despite this lack of evidence, i.v. iloprost has been approved for PAH therapy in New Zealand and has been widely administered as off-label use in Germany and other European countries. Thus, the demonstration of i.v. iloprost efficacy is an important clinical issue in PAH.

In the current issue of the European Respiratory Journal, HOEPER et al. [14] describe the long-term outcome of a German cohort of World Health Organization functional class III-IV PAH patients treated with i.v. iloprost, mainly as rescue therapy following treatment failure with first-line inhaled iloprost. These patients mainly suffered from idiopathic $\mathrm{PAH}$ or $\mathrm{PAH}$ associated with connective tissue disease. Intravenous iloprost was associated with significant short-term improvements in exercise capacity and pulmonary haemodynamics. However, long-term haemodynamic data were less impressive and the overall survival rates were extremely poor, with 1-, 3- and 5-yr survival rates from the initiation of $i . v$. iloprost of $54 \%, 31 \%$ and $15 \%$, respectively. Moreover, $26 \%$ of patients additionally underwent lung transplantation. As Germany has developed a remarkable transplant system with possible urgent listing and transplantation, overall survival could have been even worse in other countries where such a system is not yet established. In the subset of idiopathic PAH patients, the transplantationfree survival was similar to the expected survival on conventional therapy based on the haemodynamic severity at the time of i.v. iloprost initiation [15].

As acknowledged HOEPER et al. [14], the numerous biases inherent to retrospective studies make the interpretation of the data hazardous. Indeed, the study population probably represents a "negative" selection bias as the patients had extremely severe PAH at the time of i.v. iloprost initiation. More importantly, only patients who failed with first-line inhaled iloprost treatment were described [14]. One may also argue, however, that the study population may represent a "positive" selection bias of a larger group as patients who died before i.v. iloprost or were not eligible for this more aggressive therapy were not reported [14]. The comparison between the present cohort of second-line "prevalent" patients and the National Institute of Health survival model or the long-term observational series with epoprostenol [2, 3], both based on first-line "incident" cases, is thus problematic. Similar biases 
may also have influenced the long-term haemodynamic results. Finally, it remains unknown whether the long-term outcome of second-line i.v. iloprost would be similar in the current treatment era, where endothelin receptor antagonists, phosphodiesterase inhibitors and combined therapies are more commonly used. Thus, it is difficult to draw any firm conclusion from the data presented about the long-term efficacy of i.v. iloprost for PAH.

However, the study by HOEPER et al. [14] confirms that patients with poor functional capacity on therapy have extremely poor long-term prognosis. Indeed, despite what some may judge as the most advanced therapy to date, severe $\mathrm{PAH}$ remains a catastrophic disease with poorer overall survival than most advanced cancers. Importantly, the absence of survival benefit compared to the expected survival based on the National Institute of Health equation does not mean that i.v. iloprost is ineffective. In fact, data on efficacy and long-term outcomes with second-line therapies are tragically lacking in PAH. The few series [16-18] describing the long-term outcomes with rescue therapy generally reported better prognosis than in the study of HOEPER et al. [14]. Previous studies also documented that the timing of epoprostenol initiation was crucial in determining the long-term prognosis $[2,3,16]$. Whether the poor outcome described in the study by HOEPER et al. [14] is related to the initiation of second-line therapy at a later stage of the disease, the transition to a less potent rescue therapy or simply lead-time bias remains unknown. However, it certainly highlights the urgent need to consensually define treatment goals and to properly address the best therapeutic approach following failure to first-line therapy in PAH.

While the study by HoEPER et al. [14] is clearly informative regarding the outcome of patients with severe $\mathrm{PAH}$ failing on first-line therapy, numerous questions remain. Does i.v. iloprost influence the long-term outcomes of PAH? Is i.v. iloprost as effective as epoprostenol in end-stage PAH? What is the optimal dose? These unresolved questions highlight the difficulties and ethical issues of performing prospective controlled trials in devastating conditions for which alternative therapies are available. For obvious ethical reasons, long-term placebo-controlled trials to assess the effect of PAH therapies on survival are no longer possible. Short-term placebocontrolled trials would also be considered unethical in endstage PAH. We would, however, argue that using therapies with very limited evidence of efficacy to treat end-stage PAH is also questionable, given that epoprostenol has been confidently associated with survival benefit in severe PAH [1]. Some study designs, such as switch trials from epoprostenol to i.v. iloprost [6] or direct comparison between both drugs, may limit risks for patients and add confidence in using this compound. The potential pharmacological advantages of iloprost over epoprostenol and the preliminary studies with its parenteral form would certainly satisfy the principle of equipoise to justify such a trial. From our point of view, a controlled trial to confirm the clinical efficacy of i.v. iloprost in severe PAH is not only feasible but also clearly needed.

Taken together, the study from HOEPER et al. [14] certainly raises more questions than answers. It is also a humility lesson as despite recent therapeutic advances that led to improved quality of life and survival for a subset of patients [19], PAH remains a devastating disease with poor long-term survival and unsatisfactory treatment progresses for many others.

\section{STATEMENT OF INTEREST}

Statements of interest for S. Provencher and O. Sitbon can be found at www.erj.ersjournals.com $/ \mathrm{misc} /$ statements.dtl

\section{REFERENCES}

1 Barst RJ, Rubin LJ, Long WA, et al. A comparison of continuous intravenous epoprostenol (prostacyclin) with conventional therapy for primary pulmonary hypertension. The Primary Pulmonary Hypertension Study Group. N Engl J Med 1996; 334 296-302.

2 Sitbon $\mathrm{O}$, Humbert $\mathrm{M}$, Nunes $\mathrm{H}$, et al. Long-term intravenous epoprostenol infusion in primary pulmonary hypertension: prognostic factors and survival. J Am Coll Cardiol 2002; 40: 780-788.

3 McLaughlin VV, Shillington A, Rich S. Survival in primary pulmonary hypertension: the impact of epoprostenol therapy. Circulation 2002; 106: 1477-1482.

4 Simonneau G, Barst RJ, Galie N, et al. Continuous subcutaneous infusion of treprostinil, a prostacyclin analogue, in patients with pulmonary arterial hypertension: a double-blind, randomized, placebo-controlled trial. Am J Respir Crit Care Med 2002; 165 800-804.

5 Laliberte K, Arneson C, Jeffs R, et al. Pharmacokinetics and steadystate bioequivalence of treprostinil sodium (Remodulin) administered by the intravenous and subcutaneous route to normal volunteers. J Cardiovasc Pharmacol 2004; 44: 209-214.

6 Sitbon O, Manes A, Jais X, et al. Rapid switch from intravenous epoprostenol to intravenous treprostinil in patients with pulmonary arterial hypertension. J Cardiovasc Pharmacol 2007; 49: 1-5.

7 Tapson VF, Gomberg-Maitland M, McLaughlin VV, et al. Safety and efficacy of i.v. treprostinil for pulmonary arterial hypertension: a prospective, multicenter, open-label, 12-week trial. Chest 2006; 129: 683-688.

8 Olschewski H, Simonneau G, Galie N, et al. Inhaled iloprost for severe pulmonary hypertension. N Engl J Med 2002; 347: 322-329.

9 McLaughlin VV, Oudiz RJ, Frost A, et al. Randomized study of adding inhaled iloprost to existing bosentan in pulmonary arterial hypertension. Am J Respir Crit Care Med 2006; 174: 1257-1263.

10 Badesch DB, Abman SH, Simonneau G, et al. Medical therapy for pulmonary arterial hypertension: updated ACCP evidence-based clinical practice guidelines. Chest 2007; 131: 1917-1928.

11 Gomberg-Maitland M, Olschewski H. Prostacyclin therapies for the treatment of pulmonary arterial hypertension. Eur Respir J 2008; 31: 891-901.

12 Higenbottam TW, Butt AY, Dinh-Xaun AT, et al. Treatment of pulmonary hypertension with the continuous infusion of a prostacyclin analogue, iloprost. Heart 1998; 79: 175-179.

13 Higenbottam T, Butt AY, McMahon A, et al. Long-term intravenous prostaglandin (epoprostenol or iloprost) for treatment of severe pulmonary hypertension. Heart 1998; 80: 151-155.

14 Hoeper MM, Gall H, Seyfarth HJ, et al. Long-term outcome with intravenous iloprost in pulmonary arterial hypertension. Eur Respir J 2009; 34: 132-137.

15 D'Alonzo GE, Barst RJ, Ayres SM, et al. Survival in patients with primary pulmonary hypertension. Results from a national prospective registry. Ann Intern Med 1991; 115: 343-349.

16 Provencher S, Sitbon O, Humbert M, et al. Long-term outcome with first-line bosentan therapy in idiopathic pulmonary arterial hypertension. Eur Heart J 2006; 27: 589-595.

17 Hoeper MM, Markevych I, Spiekerkoetter E, et al. Goal-oriented treatment and combination therapy for pulmonary arterial hypertension. Eur Respir J 2005; 26: 858-863. 
18 Ghofrani HA, Rose F, Schermuly RT, et al. Oral sildenafil as longterm adjunct therapy to inhaled iloprost in severe pulmonary arterial hypertension. J Am Coll Cardiol 2003; 42: 158-164.
19 Galiè N, Manes A, Negro L, et al. A meta-analysis of randomized controlled trials in pulmonary arterial hypertension. Eur Heart J 2009; 30: 394-403. 